\title{
Investigating Alderfer's Work Motivation Theory to Explore Work Burnout
}

Thahira Bibi TKM Thangal, Nani llyana Shafie, Nurhazirah Mohamad Yunos, Mohd Halimi Ab Hamid, Norbaiti Sidik, Hairul Amiza Azman

To Link this Article: http://dx.doi.org/10.6007/IJARBSS/v11-i11/11305 DOI:10.6007/IJARBSS/v11-i11/11305

Received: 04 September 2021, Revised: 28 September 2021, Accepted: 15 October 2021

Published Online: 03 November 2021

In-Text Citation: (Thangal et al., 2021)

To Cite this Article: Thangal, T. B. T., Shafie, N. I., Yunos, N. M., Hamid, M. H. A., Sidik, N., \& Azman, H. A. (2021). Investigating Alderfer's Work Motivation Theory to Explore Work Burnout. International Journal of Academic Research in Business and Social Sciences, 11(11), $401-417$.

Copyright: (C) 2021 The Author(s)

Published by Human Resource Management Academic Research Society (www.hrmars.com)

This article is published under the Creative Commons Attribution (CC BY 4.0) license. Anyone may reproduce, distribute, translate and create derivative works of this article (for both commercial and non-commercial purposes), subject to full attribution to the original publication and authors. The full terms of this license may be seen

at: http://creativecommons.org/licences/by/4.0/legalcode

Vol. 11, No. 11, 2021, Pg. $401-417$

Full Terms \& Conditions of access and use can be found at http://hrmars.com/index.php/pages/detail/publication-ethics 


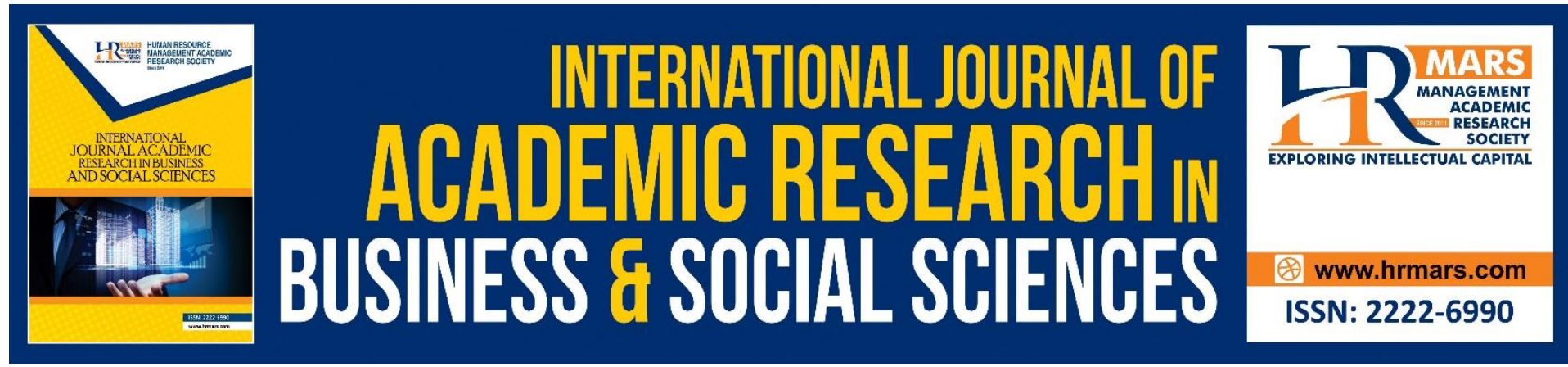

\title{
Investigating Alderfer's Work Motivation Theory to Explore Work Burnout
}

\author{
Thahira Bibi TKM Thangal ${ }^{1}$, Nani llyana Shafie ${ }^{2}$, Nurhazirah \\ Mohamad Yunos ${ }^{3}$, Mohd Halimi Ab Hamid ${ }^{4}$, Norbaiti Sidik ${ }^{5}$, \\ Hairul Amiza Azman 6
}

${ }^{1}$ Faculty of Business and Management, Universiti Teknologi MARA Cawangan Johor, Kampus Pasir Gudang, ${ }^{2}$ Faculty of Business and Management, Universiti Teknologi MARA Cawangan Selangor, Kampus Puncak Alam, ${ }^{3}$ Faculty of Computer and Mathematical Science, Universiti

Teknologi MARA, Cawangan Johor, Kampus Pasir Gudang, ${ }^{4}$ Faculty of Computer and Mathematical Science, Universiti Teknologi MARA, Cawangan Johor, Kampus Segamat, ${ }^{5}$ College of Engineering Studies, Universiti Teknologi MARA Cawangan Johor, Kampus Pasir Gudang, ${ }^{6}$ Faculty of Applied Sciences, Universiti Teknologi MARA, Cawangan Johor, Kampus Pasir Gudang

Email: thahira881@uitm.edu.my,nani.ilyana@uitm.edu.my, nurhazirah12394@uitm.edu.my, halimi@uitm.edu.my,sidiknorbaiti@uitm.edu.my, hairulamiza@uitm.edu.my

\begin{abstract}
The pandemic has changed the way people work. In the midst of excitement of working from home emerged the issue of work burnout. Work burnout is a phenomenon associated with people and their career development. Work burnout is an important risk factor for excessive stress in individual professional lives. The present study aims to explore Alderfer's Work Motivation Theory to understand work burnout. This study explores how ERG (Existence, Relatedness and Growth) Motivation influences the factors of personal, colleague and workrelated burnout. Feeling of deprivation in the working environment leads to burnout. Therefore, this research aims on personal, colleague and work-related burnout. The data conducted through a total of 100 respondents from a public university in Malaysia. The data collection using quantitative methods was performed through questionnaires and SPSS was used to summarize the demographic information and descriptive analysis. The questionnaire consists of 4 sections, a) demographic profile, b) personal burnout, c) work related burnout and d) colleague related burnout with a total of 23 items. The findings shed light on the role of work motivation in transmitting the impact of work burnout. The major contribution of the study is to understand that work motivation is indeed affecting work burnout. The study presented has profound implications for future studies of work motivation and it is hoped this study will provide valuable evidence on how to focus on personal, colleague and work-related burnout for continuous improvement.
\end{abstract}

Keywords: Alderfer's Work Motivation Theory, Work Motivation, Work Burnout, ERG. 


\section{Introduction}

Background of Study

Working online may initially sound fun due to the fact of it being new. As months (years) go by, Malaysians have to make working online a norm. While many may prefer working online, some may find that work demands may stress them out. Burnout became a hot topic after the COVID-10 pandemic shook Malaysia and the rest of the world, making 2020 a year of change in the working environment. According to Maslach and Jackson (1981), burnout is a syndrome related to a feeling of emotional exhaustion, disinterest, and reduced performance. During the pandemic, employees start to work from home or work remotely. They must adapt to new and unfamiliar work patterns, modes of communication, and team dynamics will be disrupted. Raj (2021) reported that some Malaysians are experiencing burnout due to the demands of work during the pandemic. Employees were inundated with emails and WhatsApp messages from employers and colleagues outside working hours. The future workforce will require a broad knowledge base as well as specialised skills. Hence, teaching is a demanding profession, but it is also a complex one requiring educator to be fully engaged in their work with their heads and hearts (Henny et al., 2014)

\section{Statement of Problem}

Technology makes it easier and allows employees to stay connected to the workplace at all times. According to Grant, Wallace, and Spurgeon (2013), working online is typically associated with the positive effects of increased productivity, more flexible work approaches, a reduction in work-life conflict, and an increase in job satisfaction which allows for a better balance between work and lifestyles. Besides, working online benefits both organizations and employees by improving performance, lowering transportation costs, saving time and organizational resources, and increasing employee satisfaction.

However, due to the COVID-19 pandemic, employees started to work remotely, and they struggled with long working hours and presented several complexities that may lead to burnout. Fonner and Roloff (2010) identified employees who work online have been linked to poor well-being, workplace pressure, and communication overload. It is primarily caused by long hours, endless emails and video meetings, and struggling to maintain more communication channels. According to Abdullah, Rahmat, Zawawi, Khamsah and Anuarsham (2020), employees who work online are deprived of human interaction, making them feel disconnected from the close bonds with their coworkers. As a result, work performance began to suffer, as did bonding and communication. Hence, this study is done to investigate how online learning influences engagement.

\section{Objective and Research Questions}

This study is done to answer the following questions;

1.1.1 How does Existence motivation influence personal burnout?

1.1.2 How does Relatedness motivation influence colleague related burnout?

1.1.3 How does Growth motivation influence work related burnout? 


\section{Literature Review Introduction \\ Working Online}

Working online has been discussed by researchers for the past decades. However, it has been fully adopted around the world since Covid-19 pandemic hit us. The need of limiting movement requires most companies to take drastic action by implementing working online. Previous studies had discussed the advantages and disadvantages of working online. In essence, working online requires a good internet connection, especially during a meeting and discussion where two ways communication occurs. However, according to Adnan and Anwar (2020), some of them face difficulties in accessing the internet due to technical and monetary issues. These problems may lead to miscommunication, wherein the information may not be delivered clearly or misinterpreted and the discussions may not go smoothly.

Apart from that, prior research by Shlenskaya, Karnaukhova, Son and Lapteva (2020) reported that working online has increased the time consumed in front of the computer and the difficulties in separating work as well as personal life especially when it is conducted at home. Long periods of time looking at the computer screen may affect health such as blurred vision, dry eyes and neck pain.

Looking at a positive insight reported by Ferreira, Pereira, Bianchi, and da Silva (2021) working online provided flexibility to the workers and helped them to achieve a better work life balance by allowing them to have better management to create their own schedules, which leads to increased job satisfaction. In fact, they also have flexibility in choosing a place to work in order to create a positive ambience and motivate themselves to get the work done according to their own schedule.

\section{Work Motivation}

In discussing work motivation theory, a notable theory known as Maslow's Hierarchy of Need plays an important role, as it serves as one of the basic foundations in motivation theory. Maslow's Hierarchy of Need was developed by Abraham Maslow which argues that there are five stages of human needs that motivate people's behavior (Maslow, 1954). These stages of needs function in a hierarchical manner where physiological needs (e.g., clothing, food, water) at the base of the hierarchy, followed by safety (e.g., security, shelter), belonging (e.g., friends, family, community), self-esteem (e.g., achievement, appreciation, recognition) and self-actualization (e.g., fulfilment, creativity). Maslow categorized these five needs into two categories; "deficiency needs" and "growth needs", with deficiency needs must be satisfied before moving on to the next stage. Despite being used and acknowledged in many studies, Wahba and Bridwell (1976) have disputed the validity of a fixed hierarchy of needs for every individual in Maslow's theory. Recently, Tay and Diener (2011) have shown that the hierarchy of needs fluctuates with age and does not seem to be consistent between all age groups as proposed by Maslow.

In this research, we explore another work motivation theory known as Alderfer's ERG which was devised from Maslow's five human needs but without some form of hierarchy concreteness. Clayton Alderfer introduced an alternative work motivation theory where he felt that an individual's needs vary depending on circumstances and do not have to be addressed in a fixed sequence. In other words, a lower level of need does not have to be fulfilled for a higher level to become substantial (Furnham, 2008). Alderfer's ERG theory states that there are three groups of fundamental needs; existence, a relatedness and growth (Alderfer, 1969). As stated in his theory, the existence needs include the physiological and 
safety needs of Maslow's work motivation which concern basic material and physiological wants. Next, the relatedness needs to incorporate social and external esteem; the urge to ensure personal relationships with significant others. These social and external esteem requires connection with others in order to be fulfilled and these are aligned with Maslow's belonging and self-esteem classification. Lastly, Alderfer identifies growth needs as an intrinsic desire that drives an individual to have psychological growth and productive influence on himself. These correspond to Maslow's fourth and fifth levels.

\section{Burnout}

The Copenhagen Burnout Inventory: A new tool for the assessment of burnout from the National Institute of Occupational Health, Copenhagen O, Denmark is one of the best papers to be reviewed about work burnout. Kristensen, Borrits, Villadsen, and Christensen (2005) published a research study titled The Copenhagen Burnout Inventory: A new tool for the assessment of burnout in their journal paper titled The Copenhagen Burnout Inventory: A new tool for the assessment of burnout. The Maslach Burnout Inventory (MBI), which has been frequently employed as a tool in most burnout investigations, was questioned in this paper. Furthermore, they established the Copenhagen Burnout Inventory ( $\mathrm{CBI}$ ), a novel tool that comes in three primary scales and may be used in various fields. Personal burnout, workrelated burnout, and client-related burnout are the three main scales used to measure burnout. Under the PUMA Study, the CBI instrument was utilised to investigate burnout among personnel in the human service sector (Project on Burnout, Motivation and Job Satisfaction ). The data revealed that every response rate was high and that internal reliability was very high. As a result, the three primary scales show that employees are more likely to have sleep issues, quit their jobs, use painkillers, and miss work due to work burnout in the future.

Freudenberger (1974); Maslach (1976) are credited with coining the term "burnout" in psychosocial science, according to the authors. Burnout became a metaphor among people who undertake "people work" sooner or later, according to Freudenberger and Maslach's research, and it was discovered to be a major component in psychological difficulties. In contrast to white collar groups, nurses, teachers, and social professionals in the 1970s, industrial employees are the primary focus of research, according to the authors.

During the pilot testing period, Kristensen, Borrits, Villadsen, and Christensen (2005) reviewed the burnout literature to learn more about empirical study results and burnout theories. Unfortunately, they discovered they couldn't utilise the $\mathrm{MBI}$ once the pilot research was completed, so they had to develop their own burnout measurement methods. The authors came up with six reasons for not using The Maslach Burnout Inventory (MBI) in their study. Circular argument, ambiguous relationship between the $\mathrm{MBI}$ and the idea of burnout, mixing of an individual condition, a coping strategy, and an effect, undesirable questions, what the Maslach Burnout Inventory - General Survey (MBI-GS) measure does, and public domain are the six reasons. In order to achieve their goals, the team researchers developed the $\mathrm{CBI}$, a questionnaire with three sub-sections: personal burnout, work-related burnout, and clientrelated burnout. However, they rigorously adhered to the general framework of burnout research to achieve their goals.

The authors claim that their theoretical work only differentiates between working with clients, customers, and coworkers. In the CBI, the authors plainly indicated that fatigue and 
exhaustion are at the heart of burnout. Schaufeli and Greenglass described burnout as "a state of physical, emotional, and mental weariness that occurs as a result of long-term involvement in emotionally taxing work settings" (Schaufeli \& Greenglass, 2001, p. 501). Burnout, according to Pines and Aronson, is "a state of physical and emotional weariness generated by long-term involvement in emotionally taxing situations." Burnout is defined as a mix of physical fatigue, emotional exhaustion, and cognitive weariness (Pines \& Aronson, 1988 , p. 9), while Shirom defined it as "Specifically, burnout refers to a combination of physical fatigue, emotional exhaustion, and cognitive weariness" (Shirom, 1989, p. 33).

The team researchers defined the personal burnout dimension in the first sub-dimensions $\mathrm{CBI}$ as "Personal burnout is the degree of physical and psychological fatigue and exhaustion experienced by the person," without making an attempt to differentiate between psychological and physical exhaustion or fatigue. Work-related burnout, the second subdimension of $\mathrm{CBI}$, was defined as "the degree of physical and psychological stress and exhaustion that is regarded by the person as related to his or her work." Clearly, the authors were interested in the person's tiredness as a result of their workload. Client-related burnout is the final sub-dimension of $\mathrm{CBI}$, which is defined as "the degree of physical and psychological stress and exhaustion that a person perceives as related to his or her work with clients." Client-related burnout depicts the level of fatigue and exhaustion experienced by workers as a result of their job relationships with their clients.

Kristensen et al (2005) used CBI instruments on employees in the human service industry to assess baseline and follow-up data from the PUMA project during a five-year period. The authors received responses from 1914 people from seven different organisations. 196 respondents from a state psychiatric prison, 379 respondents from a large town's social welfare office, 413 respondents from wards in a county somatic hospital, 43 respondents from a psychiatric ward in the same county, 307 respondents from severely disabled institutions in a county, 284 respondents from homecare services in the capital, and 292 respondents from homecare services in a province to complete their research. The Copenhagen Psychosocial Questionnaire influenced the majority of the PUMA questionnaire (COPSOQ). Workers' lifestyles, specialised jobs, physical and mental health and well-being, medication use, sociodemographic characteristics, absence from work, and psychosocial aspects at work, family, and work interaction were all covered in the questionnaire.

As a result, the research study concludes that the $\mathrm{CBI}$ instrument is a valid and trustworthy tool for analysing the effects of job burnout that is extensively used in a number of nations throughout the world. It has been translated into English, Swedish, French, Mandarin, Japanese, Cantonese, Finnish, and Slovenian, to name a few.

\section{Past Studies}

\section{Past Studies on work online}

Several studies have been done to find the advantages and disadvantages of working online. As reported by Michal (2021), ALDINE analysis and a meta-analysis of 20 studies along with the Wilcoxon Rank Test, a non-parametric statistic, have been used to investigate the statistical difference between the advantages and disadvantages of working online. In the study, they found that working online provided more positive benefits than negative ones, where more than half of the binomial test studies mentioned flexibility, efficiency and 
productivity, satisfaction, and Work-Life Balance (WLB). However, the downside of working online is that this method of work may pose challenges for individuals as well as teams because it is not suitable for everyone. Amongst the main disadvantages of working online are culture and family history (40\%) conflicts (35\%), isolation, stress, and depression, $25 \%$ each. Mingzhu and Douglas (2013) used a mixed-methods study technique to investigate five online graduate-level courses ( 100 students and 5 instructors) and summarize 22 participants' experiences in order to determine the benefits and drawbacks of online versus face-to-face discussion. The findings demonstrated that online small group discussions outperform faceto-face subgroup discourse. There are 16 advantages of online small group discussion outlined by the authors and some of these include increasing focus, facilitating more in-depth discussions, increasing the quality of contributions, reducing instructors' involvement, and encouraging more participation. Despite its benefits, online small group discussions have some drawbacks, including heavier workload, longer discussion times, time delays, loss of personal connection, and experiencing misunderstandings. Those findings may be relevant to practitioners of online small groups, and to the researcher looking for further research on how to achieve fruitful online discourse.

Next, the study by Izzeddin (2021) also looked at the advantages and disadvantages of working online. A descriptive-phenomenological approach was used to explore the online learning experiences of ten nursing students and ten faculty members throughout the Covid19 era. Study results identified three themes of advantages: flexibility, academic achievement, and student-centered learning. On the other hand, it revealed four themes of disadvantages: inadequacy, academic integrity, learning environment, and family burden. Nonetheless, although the respondents were somewhat fulfilled with online learning as an alternative during the Covid-19 outbreak, they preferred traditional learning methods.

The study conducted by Yi, Wei, and Pengfei (2021) also examined the advantages and disadvantages associated with working online. Regression analysis and difference-indifferences analysis was used to evaluate the efficiency of working online by comparing results of 6,701 analyst visits to 1,164 offline and online corporations. Although online visits are easier to schedule, facilitate better communication of timely information, and enhance distancing between analysts, especially during the Covid-19 pandemic, the empirical study demonstrates that analysts' projections are accurate following physical visits. Therefore, based on analyst experience, resources, business visibility, and transparency, this research implies that working online reduces forecast accuracy. This subsequently impacts overall economic productivity and market transparency.

\section{Past Studies on Work Motivation}

A series of recent studies has indicated that work motivation is justified by the job task, attitudes, and individual values (Kongcharoen et al., 2019, Chambel et al., 2020). The study by Kongcharoen et al (2019) is done to investigate issues on stress and work motivation. The purpose of the study is to examine the levels of stress and work motivation among educators. The sample consists of 400 respondents. The instrument used was questionnaire and analyzed by T-test, ANOVA and confirmatory factor analysis. This study highlights work motivation significantly related to stress. This allows the conclusion that low levels of work motivation factors can lead to stress in the working environment. 
In addition, a study done by Chambel et al (2020) revealed the impact of work motivation with workers' burnout. This study is to examine perceived overqualification and contact center workers' burnout with focusing the work motivation as mediators. The study was analyzed by using Mplus in conducting structural equation models with the participation of 3,256 contact center workers. The findings of this study did emphasize work motivation as the main factor in contributing to the burnout.

Meanwhile, Lyndon et al (2017) in their research looking into burnout, quality of life, motivation and academic achievement reveals those with lower motivational orientation did influence on their quality of life and academic achievement. The objectives of this research are to determine the relationship between burnout, quality of life, motivation and academic achievements among medical students with the approach of person oriented. The research was carried among 670 respondents using multivariate analysis of covariance methods. The research significantly indicates motivation is one of the factors to decrease anxiety and increase self-efficacy

\section{Past Studies on Burnout}

Many studies have been done to explain work burnout and researches indicate that chronic stress is one of the major causative factors of burnout (Sharma \& Cooper, 2016)

Henny et al (2014) investigate the prevalence of burnout and its associated factors among faculty members. This research focused on 194 randomly sampled academicians from a faculty of a public university. The result of this study clarified that burnout was found to be prevalent among academicians, with the overall prevalence of burnout was $10.7 \%$, with significant associations between gender, teaching experience, and job satisfaction. Meanwhile, female academicians have a higher prevalence of burnout (14.3\%).

Next, Shlenskaya et al (2020) describe the burnout and difficulties experienced by university staff while teaching full-time university students through distance learning during the coronavirus pandemic. Their studies aimed at looking at the level of burnout. This study focuses on the 66 higher education teachers. Most of them were teachers of foreign languages at universities. It was discovered that the gender of teachers had no effect on their burnout, but there were differences in the level of the components of burnout.

\section{Conceptual Framework}

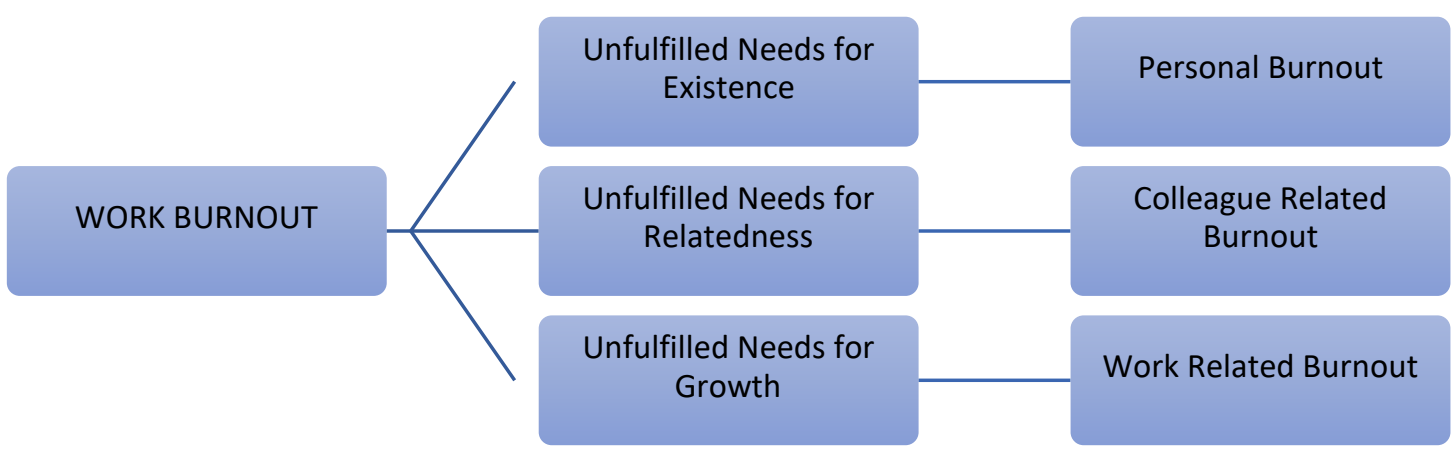

Figure 1- Theoretical Framework of the Study 
This study is rooted from Alderfer's (1969) theory of work motivation. Aldefer (1969) states that factors like existence, relatedness and growth (ERG) contribute to work motivation. However, when people have to work in conditions where all the three factors (ERG) are not fulfilled, they may end up getting work burnout. The three ERG factors are used as scaffolds to explain the link from motivation and work burnout by Kristensen et al. (2005) . With reference to Figure 1 , the unfulfilled needs for existence (E) can lead to personal burnout. Next, the unfulfilled needs for relatedness $(R)$ may lead to colleague related burnout. Finally, the unfulfilled needs for growth(G) may lead to work-related burnout.

\section{Methodology}

This quantitative study is done to explore the demotivating factors that lead to work burnout at the workplace. A total of 100 respondents from a public university in Malaysia participated in this study. The instrument (Table 1) used in this study is a survey adapted from Kristensen et al. (2005). The survey has 3 sections (not including the demographic profile. Section B has 6 items on personal related burnout. Section $C$ has 7 items on work-related burnout and section $D$ has 6 items on colleague related burnout.

Table 1-Distribution of Items in Instrument

\begin{tabular}{|l|l|l|l|}
\hline CONSTRUCTS & SECTION & HEADING & No of Items \\
\hline \multirow{3}{*}{ WORK BURNOUT } & B & Personal Related Burnout & 6 \\
\cline { 2 - 4 } & C & Work Related Burnout & 7 \\
\cline { 2 - 4 } & D & Colleague Related Burnout & 6 \\
\hline & & & 19 \\
\hline
\end{tabular}

SPSS analysis revealed a Cronbach alpha of .934 (table 2), thus revealing a high internal reliability of the instrument chosen. Data is analysed and presented in the form of percentage (for demographic profile) and mean score to answer the three research questions.

Table 2- Reliability Statistics

\section{Reliability Statistics}

\begin{tabular}{r|r}
$\begin{array}{c}\text { Cronbach's } \\
\text { Alpha }\end{array}$ & N of Items \\
\hline .934 & 19 \\
\hline
\end{tabular}

\section{Findings}

\section{Introduction}

This section presents the findings in terms of percentages for the demographic profile and mean scores for the rest of the sections. 


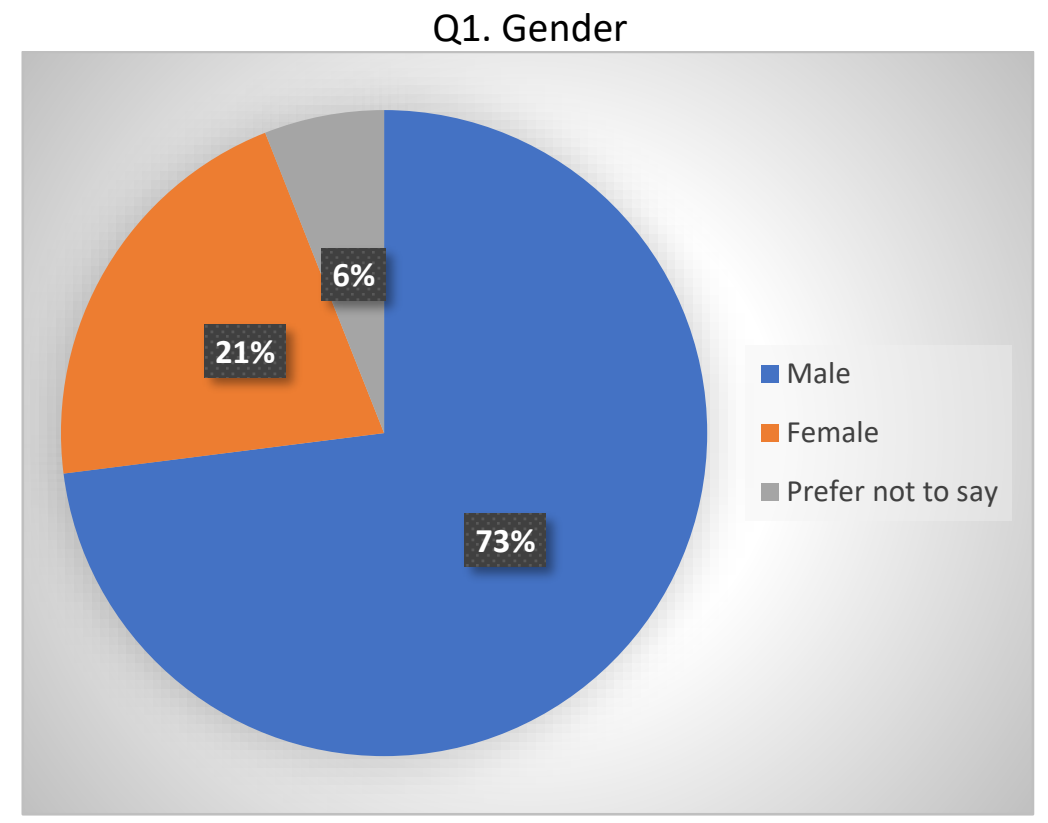

Figure 2- Percentage for Gender

Figure 2 shows the demographic of gender among respondents. The largest number of respondents were male with $73 \%$ and followed by female with $21 \%$. $6 \%$ of respondents preferred not to reveal their gender.

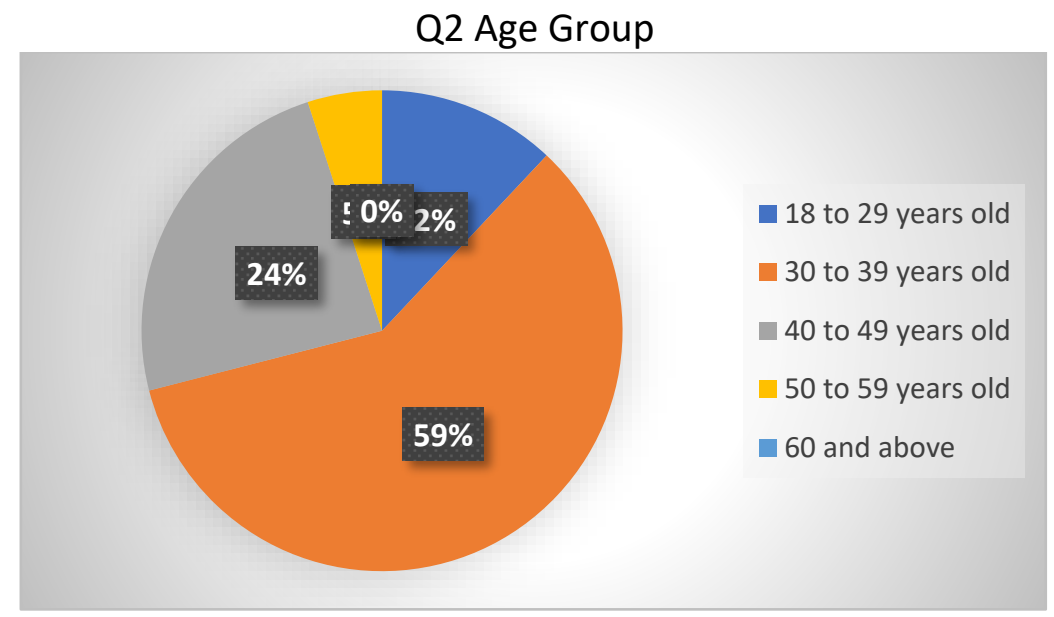

Figure 3-Percentage for Age

The data from Figure 3 reveals that most respondents were coming from the age group of 30 to 39 years old with $59 \%$ and 40 to 49 years old with $24 \%$. The remaining age group of 18 to 29 years old and 50 to 59 years old were made up of $12 \%$ and $5 \%$, respectively. None of the respondents were from the age group of 60 and above. 
Q3. Highest Academic Level

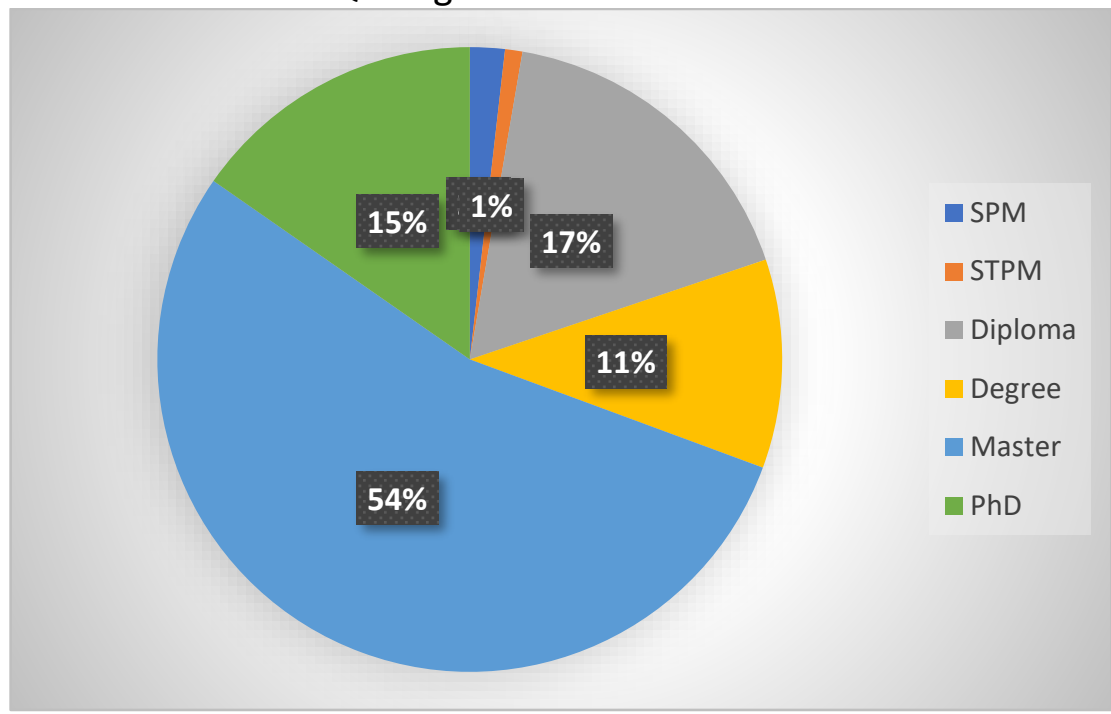

Figure 4-Percentage for Highest Academic Level

Figure 4 shows the highest academic level of respondents. $60 \%$ of respondents were Master holders. This was followed by Diploma holders with $19 \%$ and PhD holders with $17 \% .12 \%$ of the respondents held Degree. The remaining respondents were holding SPM and STPM with $2 \%$ and $1 \%$, respectively.

Q4. UiTM Branch

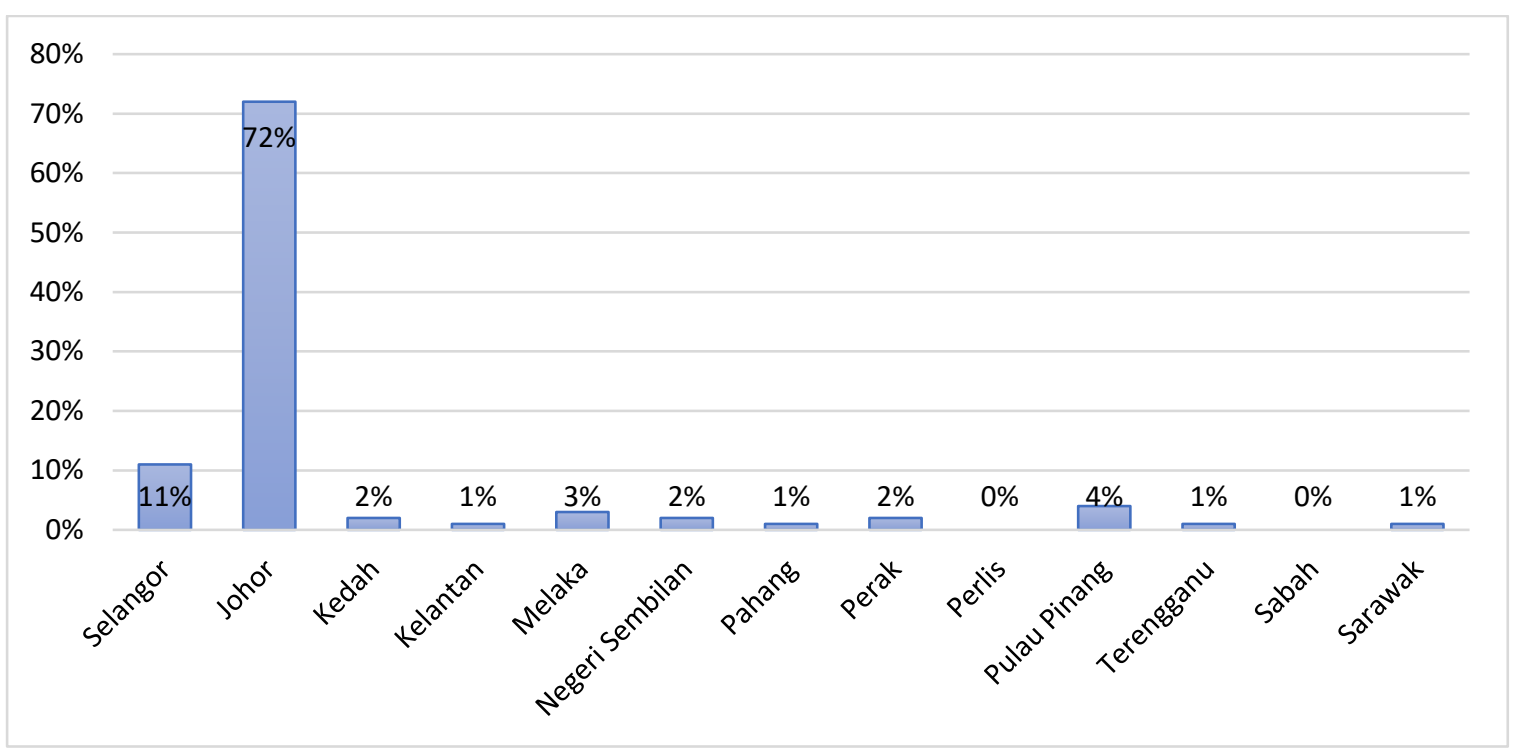

Figure 5- Percentage for State

According to Figure 5, the respondents came from various states. Most of the respondents came from Johor with $72 \%$. This was followed by respondents from Selangor with $11 \%$ and Pulau Pinang with $4 \% .3 \%$ of the respondents come from Melaka and $2 \%$ come from Kedah and Negeri Sembilan as well as Perak. The least respondents came from Kelantan, Pahang, Terengganu and Sarawak with $1 \%$. There was no respondent from Sabah. 
Q5. UiTM Staff

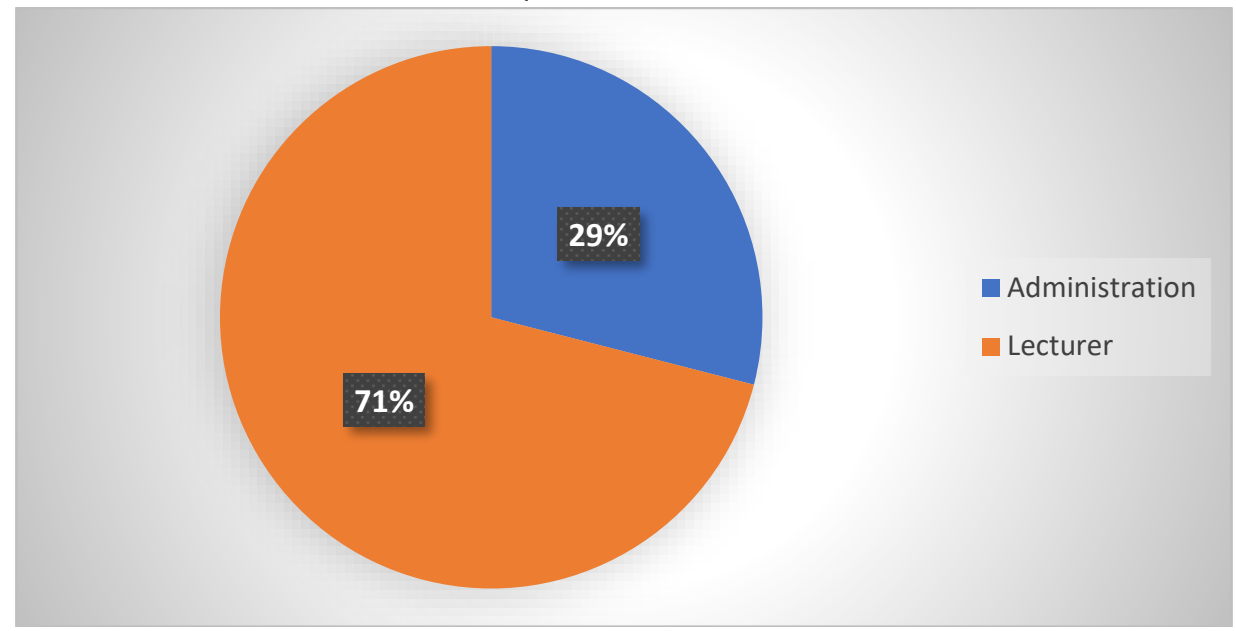

Figure 6- Percentage for UiTM Staf

The data from Figure 6 presents that $71 \%$ of the respondents were lecturers and $29 \%$ were coming from the administration.

\section{Findings for Unfulfilled Needs for Existence}

This section presents data to answer research question 1: How does Existence motivation influence personal burnout? It is when the needs for existence is not fulfilled, then the person may suffer from personal burnout.

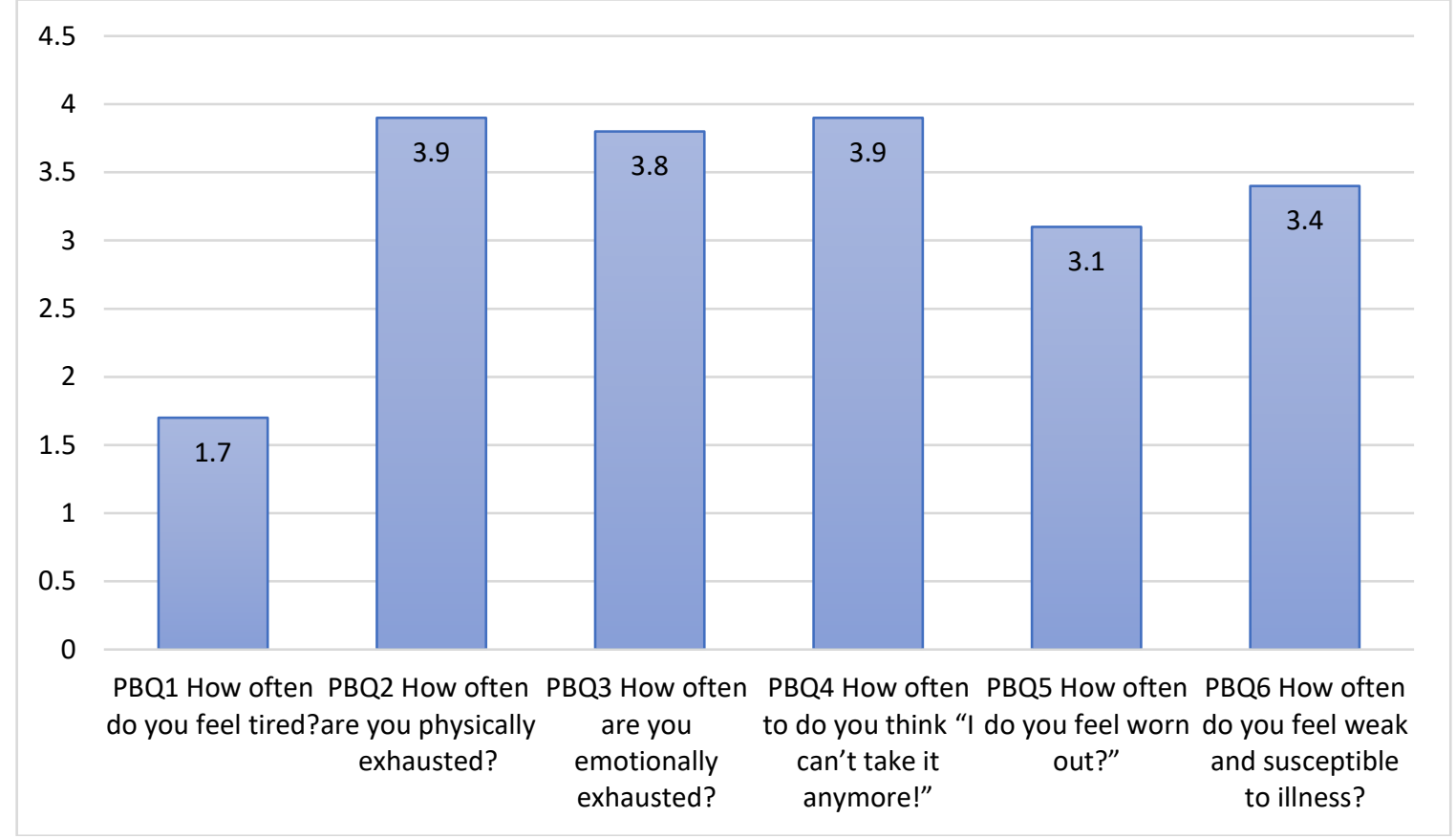

Figure 6- Mean for Personal Burnout

In this section, the mean scores associated with the respondents' personal burnout are presented. Figure 6 shows that there is no significant difference in how respondents feel about PBQ2 (How often are you physically exhausted?) and PBQ4 (How often do you think "I can't take it anymore!"), as both questions have the same mean score of 3.9. Meanwhile, the mean score obtained for PBQ3 (How often are you emotionally exhausted?) and PBQ6 (How often do you feel weak and susceptible to illness?) are 3.8 and 3.4, respectively. In response 
to PBQ5 (How often do you feel worn out?), the mean score obtained is 3.1. Lastly, the mean score for PBQ1 (How often do you feel tired?) is 1.7 in which, more than half of the respondents believe that they rarely feel tired.

Findings for Unfulfilled needs for Relatedness

This section presents data to answer research question 2: How does Relatedness motivation influence colleague related burnout? When the employee feels that his/her needs for relatedness is not fulfilled, he/she may suffer from colleague-related burnout.

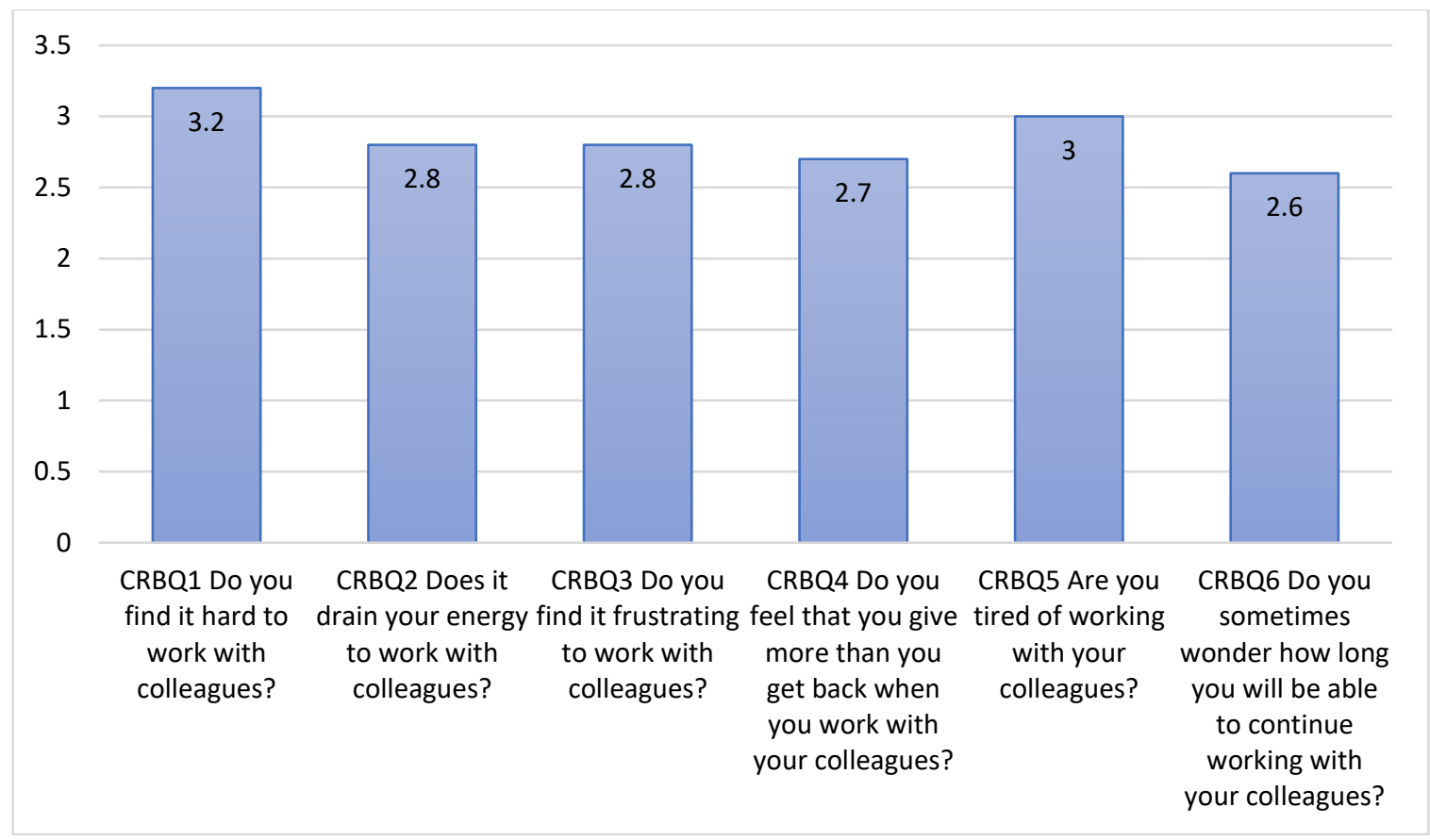

Figure 7- mean for Colleague Related Burnout

Results from figure 8: Colleague Related Burnout (CRB) are shown in Figure 7. Based on the results, the mean values for CRBQ1 (Do you find it hard to work with colleagues?) and CRBQ5 (Are you tired of working with your colleagues?) are 3.2 and 3.0 respectively. As for CRBQ2 (Does working with colleagues drain your energy?) and CRBQ3 (Is it frustrating to work with colleagues?) results show similar responses at mean value 2.8 . In this section, the lowest mean value is 2.6, which corresponds to CRBQ6 (Do you sometimes wonder how long you will be able to continue working with your colleagues?).

Findings for Unfulfilled Needs for Growth

This section presents data to answer research question 3: How does Growth motivation influence work related burnout? When employees feel that needs for growth are not fulfilled, they may suffer from work-related burnout. 


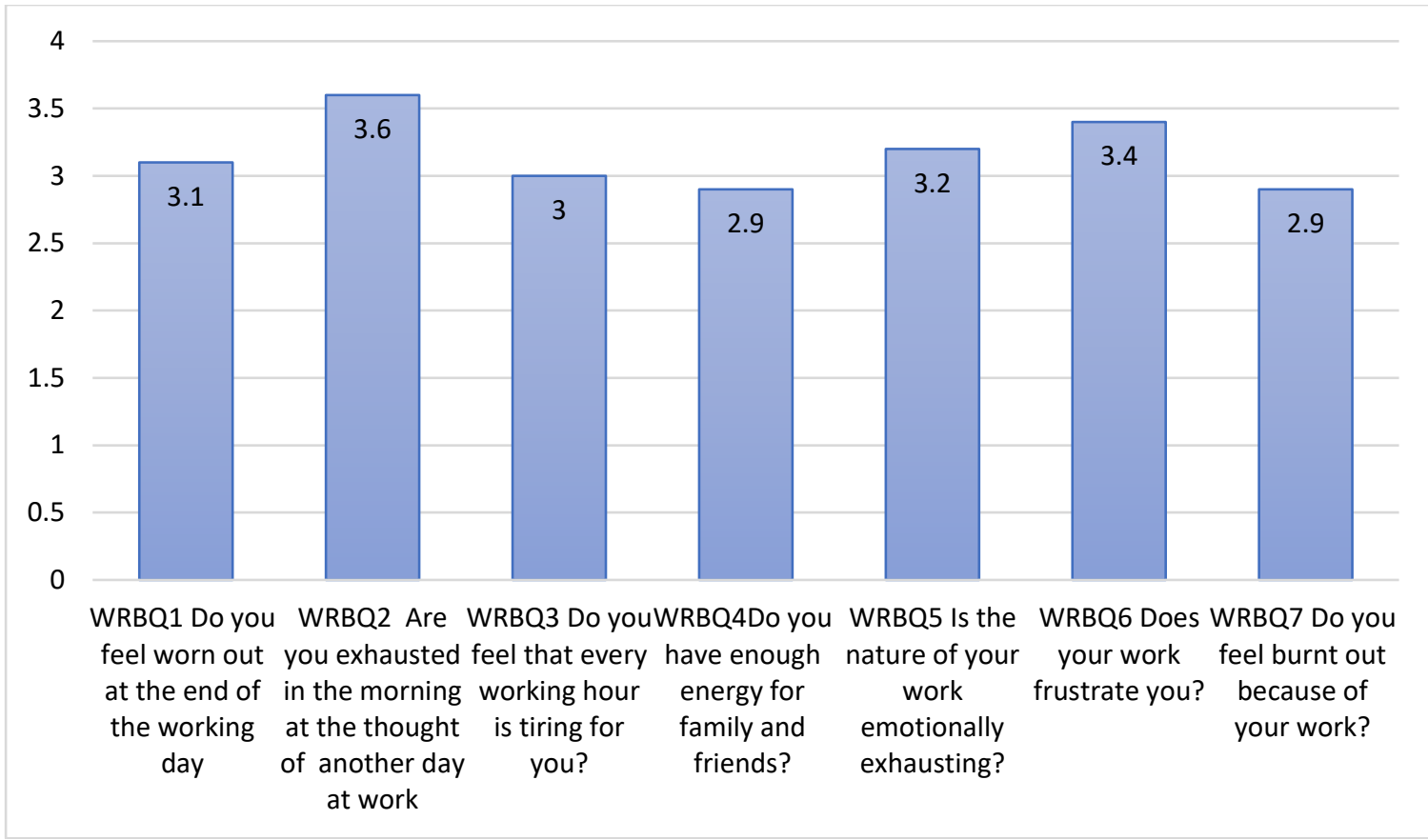

Figure 8- Mean for Work Related Burnout

Table 8 which is about work-related burnout summarizes the whole seven percentage graphs into their mean readings respectively. The result shows the mean score value of 3.1 among the respondents for the question "Do you feel worn out at the end of the working day?". The second question "Are you exhausted in the morning at the thought of another day at work?" shows the mean reading of 3.6 among them. For the third question, "Do you feel that every working hour is tiring for you?" the mean score value is 3 . The result also shows the mean value of the respondents is 2.9 for the question "Do you have enough energy for family and friends?". The mean value of the respondents was recorded as 3.2 for the question "Is the nature of your work emotionally exhausting?". The sixth question "Does your work frustrate you?" shows the highest mean reading of 3.4 among the respondents and the last question "Do you feel burnt out because of your work?" tabulated the mean reading as the lowest reading which is 2.9 among the respondents.

\section{Conclusion}

\section{Summary of Findings and Discussion}

This study has identified the state of personal burnout in the category of "How often are you physically exhausted?" and "How often do you think I can't take it anymore!", have the same mean value of 3.9. It is interesting to note that even the mean value for personal burnout is moderately high compared to the only item "How often do you feel tired" with a 1.7 mean score value. The item in this component justified that the level of burnout (Henny et al., 2014) among colleagues was low compared to work related burnout. This result may be explained by the fact that respondents were not facing problems in their personal matters due to the situation of working online with the family and feeling content in the house. It is somewhat surprising that working online at home did not trigger the respondents' tiredness. Then, moving to the component of work-related burnout, in this study found that all the items in this component showed average mean score at 3.2. These results reflect those of Chambel et al (2020) who also found that working online do associate with burnout. This finding confirms that feeling tired, exhausted in the morning, not having enough time with family and work- 
related tasks did contribute to burnout. In general, somehow some results table out as perceived indifferently. This interpretation can be seen from Figure 8. Similarly, Shlenskaya et al (2020) also justified the findings as differences according to each item in burnout. This highlights the results of this study which explains the average mean score value for colleague related burnout. Interestingly, this finding is not in accordance with Shlenskaya et al. (2020) about not being affected by burnout. This could be due to the different culture in the working environment and the aid assisted by the colleagues in reducing the workloads. It can thus be suggested that these variations of findings differ with each component due to the state of occurrence for personal, work-related and colleague burnout. Therefore, work motivations could be a major factor in relation to burnout. Hence, it could conceivably be concluded that work motivation in working online is crucial to reduce the level of burnout.

\section{Implications and Suggestions for Future Research}

From the higher learning educators' point of view, among the various sociodemographic and job levels included in this study, work motivation was not significantly associated with burnout in this study. Further research is needed to investigate the factors that could influence burnout among higher learning educators. Employers can create programs to assist educators who have been identified as being at risk of burnout and peer support to enable improvement.

\section{References}

Abdullah, N. A. A., Rahmat, N. H., Zawawi, F. Z., Khamsah, M. A. N., \& Anuarsham, A. H. (2020). COPING WITH POST COVID-19: CAN WORK FROM HOME BE A NEW NORM?. European Journal of Social Sciences Studies, 5(6).https://oapub.org/soc/index.php/EJSSS/article/view/933

Abraham, M. (1954). Motivation and personality. Nueva York: Harper \& Row Publishers.

Adnan, M., \& Anwar, K. (2020). Online Learning amid the COVID-19 Pandemic: Students' Perspectives. Online Submission, 2(1), 45-51. http://www.doi.org/10.33902/JPSP. 2020261309.

Alderfer, C. P. (1969). "An empirical test of a new theory of human needs". Organizational Behavior and Human Performance. 4 (2): 142-75. https://doi:10.1016/00305073(69)90004-X

Chambel, M. J., Carvalho, V. S., Lopes, S., Cesario, F. (2020). Perceived overqualification and contact center worker' burnout: are motivations mediators?. International Journal of Organizational Analysis. 29(5). Pp. 1337-1349. https://10.1108/ijoa-08-2020-2372

Grant, C. A., Wallace, L. M., \& Spurgeon, P. C. (2013). An exploration of the psychological factors affecting remote e-worker's job effectiveness, well-being and work-life balance. Employee Relations. https://doi.org/10.1108/ER-08-2012-0059

Ferreira, R., Pereira, R., Bianchi, I. S., \& da Silva, M. M. (2021). Decision Factors for Remote Work Adoption: Advantages, Disadvantages, Driving Forces and Challenges. Journal of Open Innovation: Technology, Market, and Complexity, 7(1), 70. https://doi.org/10.3390/joitmc7010070.

Fonner, K. L., \& Roloff, M. E. (2010). Why teleworkers are more satisfied with their jobs than are office-based workers: When less contact is beneficial. Journal of Applied Communication Research, 38(4), 336-361.

https://doi.org/10.1080/00909882.2010.513998 
Furnham, A. (2008). The psychology of behaviour at work (2nd ed.). Hove and New York: Psychology Press.

Henny, J., Anita, A. R., Hayati, K. S., \& Rampal, L. (2014). Prevalence of burnout and its associated factors among faculty academicians. Malaysian Journal of Medicine and Health Sciences, 10(1), Retrieved from https://www.ncbi.nlm.nih.gov/pmc/issues/218858/

Izzeddin, A. B. (2021). Nursing students' and faculty members' perspectives about online learning during COVID-19 pandemic: A qualitative study. Teaching and Learning in Nursing, 16, 220-226. Retrieved from https://doi.org/10.1016/j.teln.2021.02.008

Kongcharoen, J., Onmek, N., Jandang, P., \& Wangyisen, S. (2019). Stress and work motivation of primary and secondary school teachers. Journal of Applied Research in Higher Education, 12(4), 709-723. doi:10.1108/jarhe-04-2019-0088

Kristensen,T.S., Borrits,M., Villadsen,E., \& Christensen,K.B. (2005) The Copenhagen Burnout Inventory: A New Role for the Assessment of Burnout. Work \& Stress, Vol 19(3), pp 192-207. Retrieved from https://doi.dx/ 10.1080/02678370500297720

Lyndon M.P., Henning M.A., Alyami H., Krishna S., Zeng I., Yu T.C., Hill A.G. (2017). Burnout, quality of life, motivation and academic achievement among medical students : A person-oriented approach. Perspect Med. Education. 6. Pp 1108-114. https://10.1007/s40037-017-0340-6

Maslach, C., \& Jackson, S. E. (1981). The measurement of experienced burnout. Journal of organizational behavior, 2(2), 99-113.

McCormick, J., \& Barnett, K. (2011). Teachers' attributions for stress and their relationships with burnout. International journal of educational management.https://www-emeraldcom.ezaccess.library.uitm.edu.my/insight/content/doi/10.1108/ITSE-05-20200066/full/pdf?title=effect-of-e-evaluation-on-work-motivation-among-teachersduring-the-movement-control-order-in-covid-19-the-mediating-role-of-stress

Michal, B. (2021). Advantages and disadvantages of E-working: An examination using an ALDINE analysis. Emerging Science Journal, 5, 11-20. Retrieved from https://doi.org/10.28991/esj-2021-SPER-02

Mingzhu, Q., \& Douglas M. (2013). Foster strengths and circumvent weaknesses: Advantages and disadvantages of online versus face-to-face subgroup discourse. Computers \& Education, 67, 1-11. Retrieved from https://doi.org/10.1016/j.compedu.2013.02.005

Pines, A., \& Aronson, E. (1988). Career burnout: Causes and cures. New York: The Free Press.

Qureshi, S. (2013). The relationship between work motivation, burnout and intention to leave for the top level managers of garment industry (a case study of Indian garment industry). International Journal of Human Resource Studies, 3(4), 128. https://www.macrothink.org/journal/index.php/ijhrs/article/view/4609

Raj, M. R. (2021). 'Covid-19: Some Malaysian educators face burnout due to demands of teaching during pandemic. Malay Mail.

https://www.malaymail.com/news/life/2021/03/19/covid-19-some-malaysianeducators-face-burnout-due-to-demands-of-teaching-d/1959179

Ryan, R. M., \& Deci, E. L. (2000). Self-determination theory and the facilitation of intrinsic motivation, social development, and well-being. American psychologist, 55(1), 68. https://doi.org/10.1037//0003-066x.55.1.68

Schaufeli, W. B., \& Greenglass, E. R. (2001). Introduction to special issue on burnout and health. Psychology and Health, 16, 501/10.

https://doi.org/10.1080/08870440108405523 
Sharma, R. R., \& Cooper, C. (2016). Stress and Burnout: An Introduction. In Executive Burnout. Emerald Group Publishing Limited. https://doi-org.ezaccess.library.uitm.edu.my/10.1108/978-1-78635-286-620161001

Shin, H., Park, Y. M., Ying, J. Y., Kim, B., Noh, H., \& Lee, S. M. (2014). Relationships between coping strategies and burnout symptoms: A meta-analytic approach. Professional Psychology: Research and Practice, 45(1), 44.https://psycnet.apa.org/doi/10.1037/a0035220

Shirom, A. (1989). Burnout in work organizations. In C. L. Cooper, \& I. T. Robertson (Eds), International review of industrial and organizational psychology (pp. 25/48). New York: Wiley

Shlenskaya, N., Karnaukhova, A., Son, L., \& Lapteva, E. (2020). Teachers' burnout in online university courses in the time of pandemic. In 2020 The 4th International Conference on Education and Multimedia Technology (pp.95-99). https://doi.org/10.1145/3416797.3416841.

Tay, L. and Diener, E. (2011). Needs and subjective well-being around the world. Journal of Personality and Social Psychology, 101(2): 354-365. https://doi.org/10.1037/a0023779

Ugwu, F. O., Onyishi, I. E., \& Tyoyima, W. A. (2013). Exploring the relationships between academic burnout, self-efficacy and academic engagement among Nigerian college students. In The African Symposium (Vol. 13, No. 2, pp. 37-45). Retrieved from https://citeseerx.ist.psu.edu/viewdoc/download?doi=10.1.1.732.4959\&rep=rep1\&typ $\mathrm{e}=\mathrm{pdf}$

Waddell, D., Devine, J., Jones, G. R., \& George, J. M. (2007). Contemporary management. Mc Graw Hill Irwin.

Wahba, M. A., \& Bridwell, L. G. (1976). Maslow reconsidered: A review of research on the need hierarchy theory. Organizational Behavior and Human Performance, 15, 212-240. https://doi.org/10.1016/0030-5073(76)90038-6

Yi, L., Wei, Z., \& Pengfei, W. (2021). Working online or offline: Which is more effective?. Research in International Business and Finance, 58, 1-19. Retrieved from https://doi.org/10.1016/j.ribaf.2021.101456 